\title{
Foliar applied brassica water extract improves the seedling development of wheat and chickpea
}

\author{
Omer Farooq ${ }^{1}$, Muqarrab Ali², Naeem Sarwar ${ }^{1}$, Atique ur Rehman', Muhammad Mazhar Iqbal ${ }^{3}$, Tayyaba \\ Naz $^{4}$, Muhammad Asghar ${ }^{1}$, Fahid Ehsan ${ }^{5}$, Muhammad Nasir1', Qari Muhammad Hussain ${ }^{1}$, Sohaib Afzal ${ }^{1}$ \\ ${ }^{1}$ Department of Agronomy, Bahauddin Zakariya University, Multan, Pakistan \\ ${ }^{2}$ Department of Agronomy, MNS University of Agriculture, Multan, Pakistan \\ ${ }^{3}$ Soil and Water Testing Laboratory, Department of Agriculture, Government of Punjab, Chiniot, Pakistan \\ ${ }^{4}$ Institute of Soil and Environmental Sciences, University of Agriculture, Faisalabad, Pakistan \\ ${ }^{5}$ Regional Agricultural Economic Development Centre, Vehari, Pakistan
}

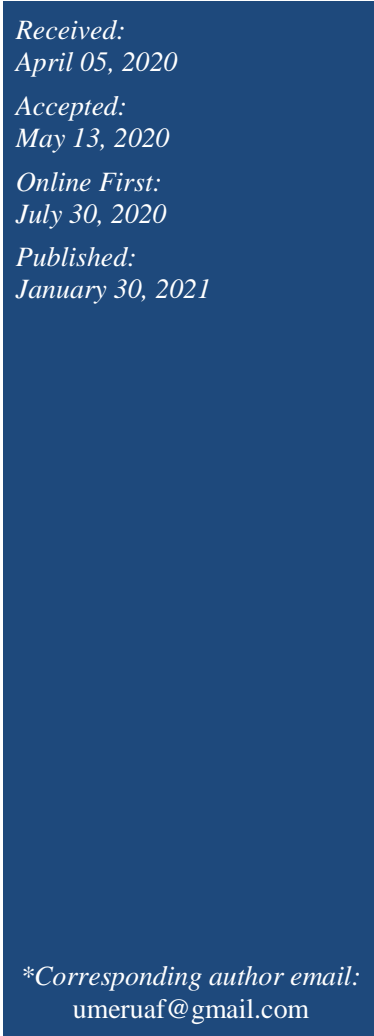

\section{Abstract}

An experiment was conducted to check the brassica water extract as natural growth regulator in improving the seedling development of wheat and chickpea. Experimental treatments included five low concentration levels of brassica water extract as $1 \%, 1.5 \%$, $2 \%, 2.5 \%$ and $3 \%$ as foliar spray. Two other treatments where no spray and water was used as foliar spray, were considered as control treatments. To compare the efficacy of natural growth regulator, a synthetic source was also maintained among foliar sprays in the form of 6-Benzylaminopurine. In conclusion, results of the experiment concluded that $2 \%$ brassica water extract was most effect level to maximally boost the seedling characteristics like shoot/root biomass, shoot/root length and number of leaves till 20 days after germination. However, this level varied in case of chickpea where a bit higher concentration, $3 \%$ yielded maximum outcomes to the recorded parameters. So, findings of the study suggest that growth promotion potential of crops like brassica should be exploited in sustainable agriculture systems.

Keywords: Crop extract, Growth regulators, Seedling enhancement, Foliar spray

\section{How to cite this:}

Farooq O, Ali M, Sarwar N, Rehman A, Iqbal MM, Naz T, Asghar M, Ehsan F, Nasir M, Hussain QM and Afzal S, 2021. Foliar applied brassica water extract improves the seedling development of wheat and chickpea. Asian J. Agric. Biol. 2021(1). DOI: https://doi.org/10.35495/ajab.2020.04.219

This is an Open Access article distributed under the terms of the Creative Commons Attribution 3.0 License. (https://creativecommons.org/licenses/by/3.0), which permits unrestricted use, distribution, and reproduction in any medium, provided the original work is properly cited.

\section{Introduction}

All species belong to brassicaceae family are assumed to have allelopathic potential (Rehman et al., 2013). Cultivated as well as wild species of brassica are allelopathic in nature and natural weed suppressor, likewise; Siemens et al. (2002) suggested that mustard in wild is successful intruders of native grassland.
Allelopathy, as a phenomenon of biochemical interaction among living organisms has both direct as well as indirect influence. These biochemicals or allelochemicals can be released from plant residues or as leachates from roots, stems, fruits, leaves and seeds also to show allelopathic activity (Ashrafi et al., 2008; Asgharipour and Armin, 2010). Further, these allelochemicals have both inhibitory and promotive 
effects on the receiving plants, accordingly can act as natural growth promoters or natural pesticides (Chon and Kim, 2002).

Several species of Brassicaceae family were reported to have allelopathic potential by influencing the germination as well as seedling emergence of different plants (Haramoto and Gallandt, 2004). While, many putative allelochemicals have been isolated from Brassicaceae and their allelopathic potential was demonstrated in various bioassays. Furthermore, an important allelopathic compound namely glucosinolates which is present in all plant parts, however, its concentration is not uniform in all plant parts.

Allelopathy of brassica species can also be exploited in both ways of growth stimulation and inhibition. Brassinolide is naturally occurring plant hormone in brassica which shows growth promoting activity (Wada et al., 1981). To evaluate the allelopathic activity of brassica extract, germination bioassays are usually conducted to check the sensitivity of test species (Kordali et al., 2007). Keeping in view these information, a bioassay was planned to check the response of aqueous extract of brassica in various concentrations against the seedling growth of wheat and chickpea. The hypothesis of this bioassay was that brassica extract containing allelochemicals when applied in lower concentrations will enhance the growth of both test crops, representative of monocot and dicot.

\section{Material and Methods}

Brassica water extract in various lower concentrations was investigated in a glasshouse experiment. The site was located at $30.10^{\circ} \mathrm{N}, 71.25^{\circ} \mathrm{E}$ with altitude of 128 masl.

\section{Experimental details}

Small pots filled by 250 grams of pre-washed sand were used. These were arranged in completely randomized design (CRD) with eight treatments while, replicated three times. Seven seeds of wheat (Triticum aestivum L.) and chickpea (Cicer arietinum L.) were planted in every pot. At final emergence, these pots were retained to only 4 seedlings by thinning. Foliar application was done 10 days after sowing (DAS) as per treatments, $\mathrm{T}_{0}=$ no spray, $\mathrm{T}_{1}=$ simple water as foliar spray, $\mathrm{T}_{2}=1 \%$ brassica water extract (BWE), $\mathrm{T}_{3}=1.5 \%$ BWE, $\mathrm{T}_{4}=2 \% \mathrm{BWE}, \mathrm{T}_{5}=$ $2.5 \%$ BWE, $\mathrm{T}_{6}=3 \% \quad \mathrm{BWE}$ and $\mathrm{T}_{7}=5 \mathrm{ppm} \quad 6-$ Benzylaminopurine (BAP). Seedlings were subsequently irrigated with distilled water when needed up to 20 days after germination.

\section{Extract preparation}

For the preparation of BWE; rapeseed (Brassica napus L.) was harvested at maturity and preserved to dry over duration of 2 weeks at some shady place. After complete drying, this plant material was chopped in to small pieces and one $\mathrm{kg}$ of this was soaked in ten liters of normal irrigation water for twenty four hours. After the required soaking time the filtrate was passed through thin muslin cloth to get pure extract free from all impurities. Now the volume of this material was reduced to twenty times by subsequently boiling at $100^{\circ} \mathrm{C}$ temperature. This final material was considered as pure $100 \%$ BWE and collected in pre-washed bottle and stored in refrigerator until applications.

\section{Observations}

All the seedlings were harvested after 20 days of foliar applications. Data was recorded for the following parameters; root-shoot length $(\mathrm{cm})$, root-shoot biomass (g), and final leaf numbers. Root-shoot lengths were measured with a measuring scale. Whereas, after taking fresh weights with a digital balance seedling were placed in a hot air oven for 48 hours at $72^{\circ}$ centigrade for complete drying and further weighed. Leaves were manually counted to get the number of leaves per plant.

All the recorded data was examined statistically by procedure devise by Steel et al. (1997).

\section{Results}

\section{Wheat parameters \\ Root and shoot length}

All the foliar application of BWE treatments significantly influenced the root and shoot length of wheat seedling (Fig. 1). Maximum root and shoot length of wheat was recorded at $2 \%$ foliar application of BWE in comparison to all other applications. While, statistically similar improvement of root and shoot length of wheat was recorded with foliar application of BAP at $5 \mathrm{ppm}$. Whereas, minimum root and shoot length of wheat was achieved in first two treatments where no spray and water was applied as foliar spray. Enhancing the level of BWE beyond 2\% could not further improve the root and shoot length of wheat but in comparison to control applications all the concentrations of BWE improve the both parameters of wheat (Fig. 1). 

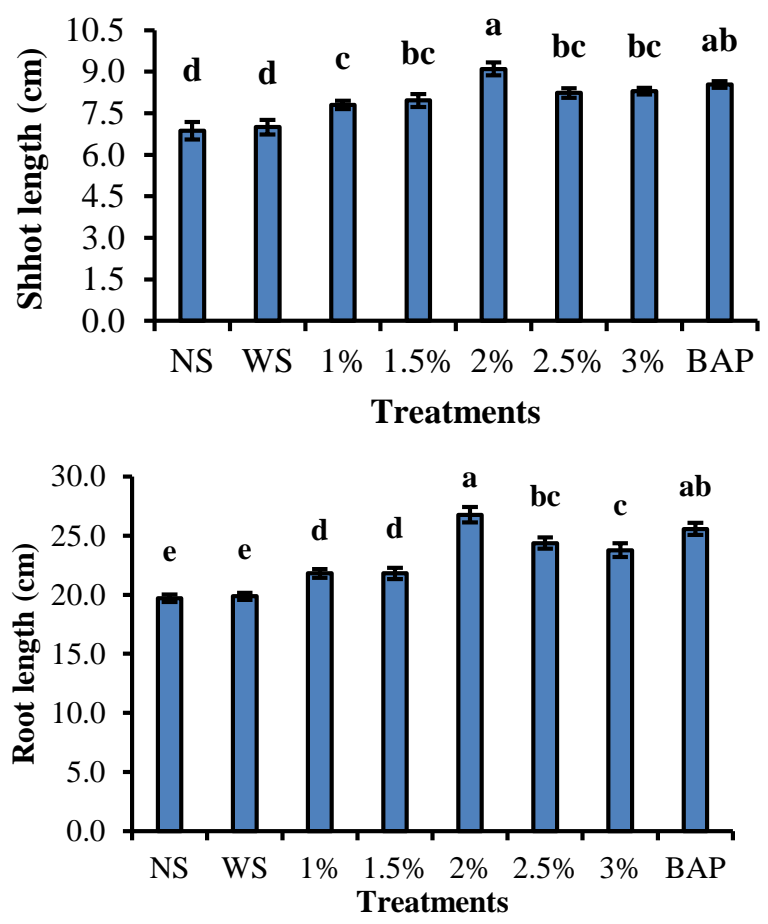

Figure-1. Shoot length (left) and root length (right) of wheat as influened by different concentrations of BWE. $\mathrm{NS}=$ No Spray, WS $=$ Water Spray, $\mathbf{B A P}=$ 6Benzylaminopurine

\section{Root and shoot biomass of wheat seedling}

In biomass, root and shoot fresh weight and dry weight was recorded. Similar to root and shoot length, all the concentrations of BWE foliar sprays significantly improved the root and shoot biomass of wheat seedling (Fig. $2 \& 3$ ). Maximum shoot fresh and dry weight was recorded at $2 \%$ foliar application of BWE in comparison to all other treatments. While, statistically similar measurements of shoot fresh and dry weight were recorded with BAP application as foliar spray. However, minimum fresh and dry weights of shoot were recorded in both control treatments where no spray and water spray was applied (Fig. 2).

In case of root fresh and dry weights, maximum values were recorded again at $2 \%$ concentration of BWE as foliar spray. Statistically similar measurement of root fresh weight was recorded with BAP application but in case of root dry weight, BAP application did not give similar results but followed the $2 \% \mathrm{BWE}$ application (Fig. 3). However, enhancing the level of BWE beyond $2 \%$ could not further improve the root and shoot biomass but in comparison to control applications all the concentrations of BWE improve the biomass of root and shoot (Fig. $2 \& 3$ ).
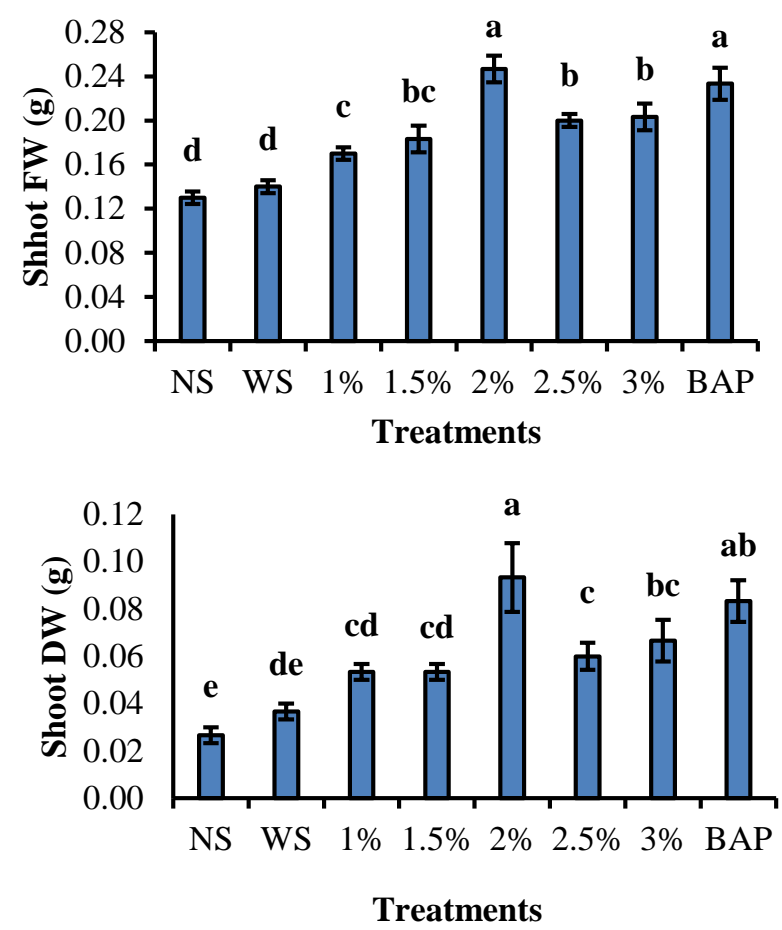

Figure-2. Shoot fresh weight (left) and shoot dry weight (right) of wheat as influened by different concentrations of BWE. NS= No Spray, WS= Water Spray, BAP= 6Benzylaminopurine
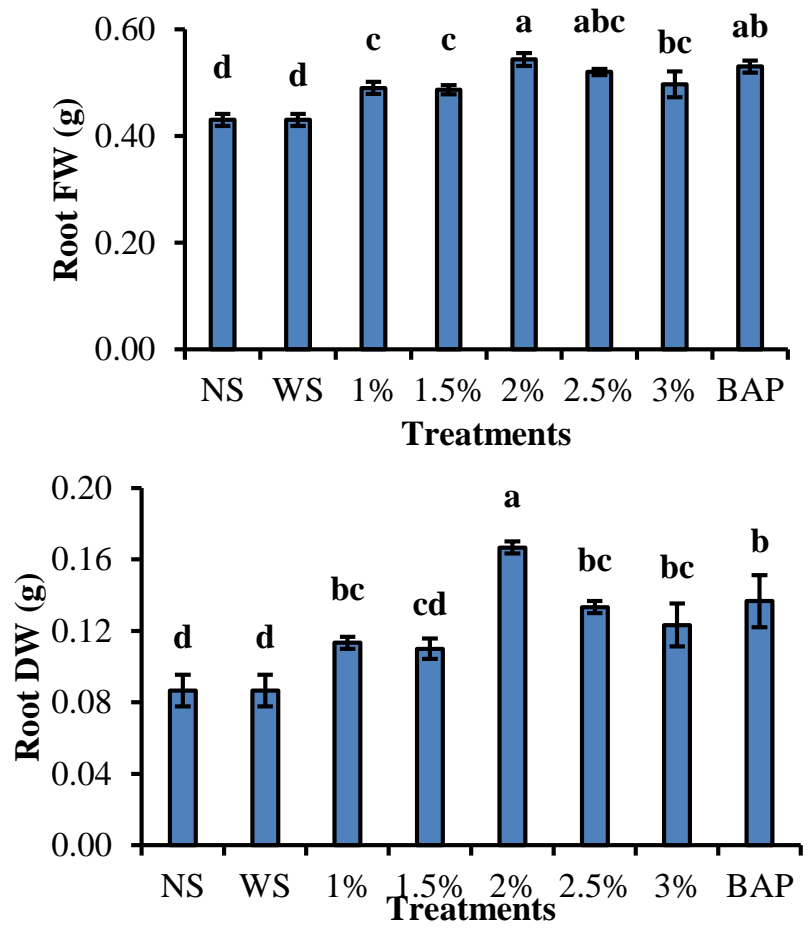

Figure-3. Root fresh weight (left) and root dry weight (right) of wheat as influened by different concentrations of BWE. NS= No Spray, WS= Water Spray, BAP= 6Benzylaminopurine 
No. of leaves of wheat and chickpea seedlings

Data regarding number of leaves of wheat as influenced by different foliar applications showed statistically significant results (Fig. 4). In case of wheat, maximum number of leaves were counted, where BWE was applied as foliar spray at $2 \%$ concentration and statistically similar number was recorded in case of BAP application. While, increasing the concentration of BWE beyond $2 \%$ could not enhance the number of leaves rather decreased the count. However, in comparison to no application treatment, all other application enhance the leaves of wheat (Fig. 4).

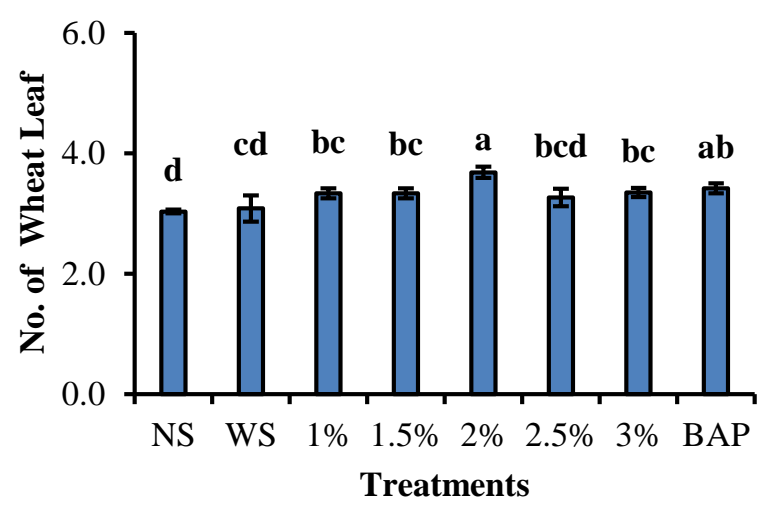

Figure-4. No. of leaves of wheat as influened by different concentrations of BWE. NS= No Spray, WS= Water Spray, BAP= 6-Benzylaminopurine

\section{Chickpea parameters \\ Root and shoot length}

Foliar application of all the treatments revealed a significant influence on the root and shoot length of chickpea seedling (Fig. 5). In comparison to all treatments, highest root and shoot length of chickpea was recorded when BWE at 3\% was applied as foliar spray. In shoot length, this was followed by foliar application of lower concentrations of BWE at $1 \%$, $1.5 \%, 2 \%$ and BAP while, in case of root length this was followed by lower concentrations foliar applications of BWE at 1.5\%, 2\% and 2.5\% (Fig. 5). Whereas, minimum root and shoot length of chickpea was noted in treatments where no spray and water as foliar spray was applied. For root growth of chickpea BAP could not give very good results (Fig. 5)

\section{Root and shoot biomass of chickpea seedling}

Like to root and shoot length, all the concentrations of BWE foliar sprays significantly improved the root and shoot biomass of chickpea seedling (Fig. $6 \& 7$ ). Highest shoot fresh and dry weights were recorded at $3 \%$ foliar application of BWE in comparison to all other treatments. Regarding shoot fresh weight, BAP application at $5 \mathrm{ppm}$ gave statistically similar results, while, other low concentration applications of BWE at $2 \%$ and $2.5 \%$ followed it. But for shoot dry weight, BAP and $2 \%$ of BWE foliar sprays followed the maximum dry weight (Fig. 6). Whereas, lowest fresh and dry weights of shoot were noted where no any spray was done (Fig. 6).
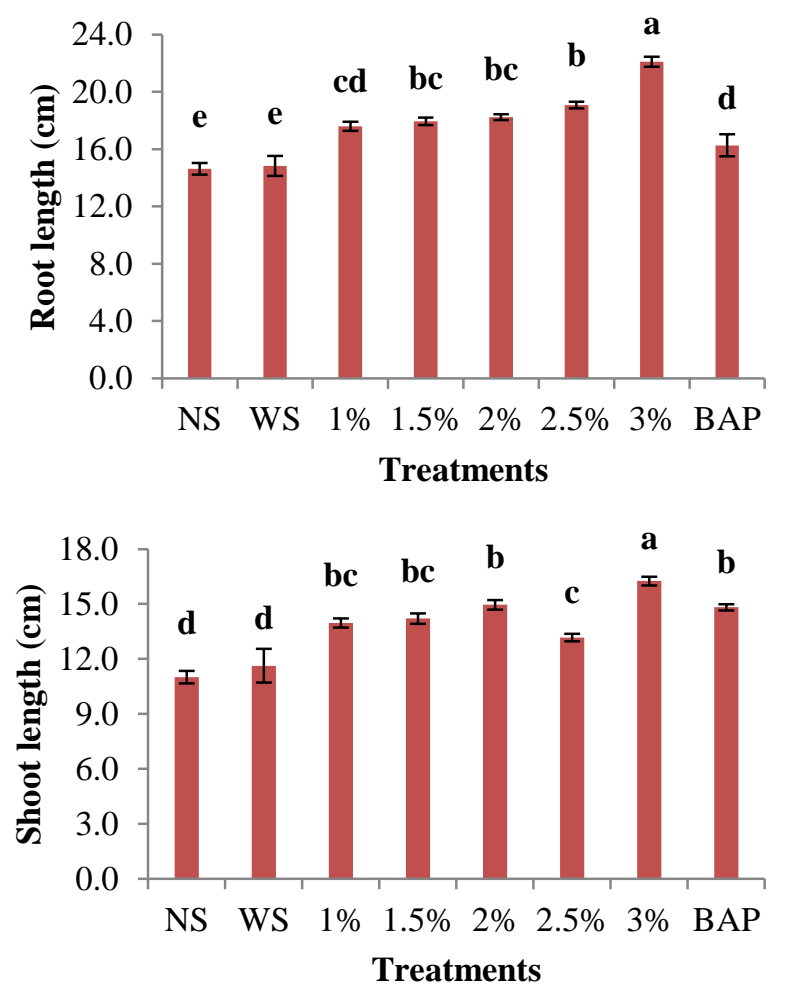

Figure-5. Shoot length (left) and root length (right) of chickpea as influened by different concentrations of BWE. NS= No Spray, WS= Water Spray, BAP = 6-Benzylaminopurine

In case of root fresh and dry weights, highest values were obtained at 3\% BWE applied as foliar spray. This was followed by BAP application along with lower dose applications of BWE at 1.5\% and 2\% (Fig. 7). Minimum values for fresh weight of roots of chickpea was recorded where no spray and water application as foliar spray was done, whereas, for dry weight minimum values were recorded where nothing was sprayed (Fig. 7). 

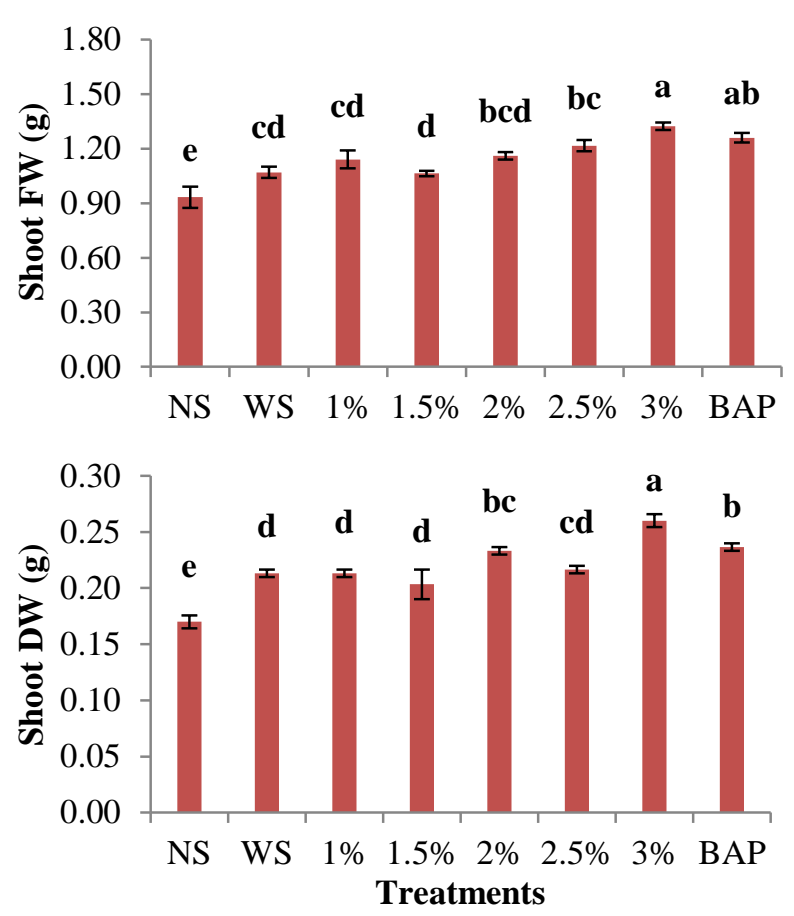

Figure-6. Shoot fresh weight (left) and shoot dry weight (right) of chickpea as influened by different concentrations of BWE. NS $=$ No Spray, WS $=$ Water Spray, BAP= 6-Benzylaminopurine

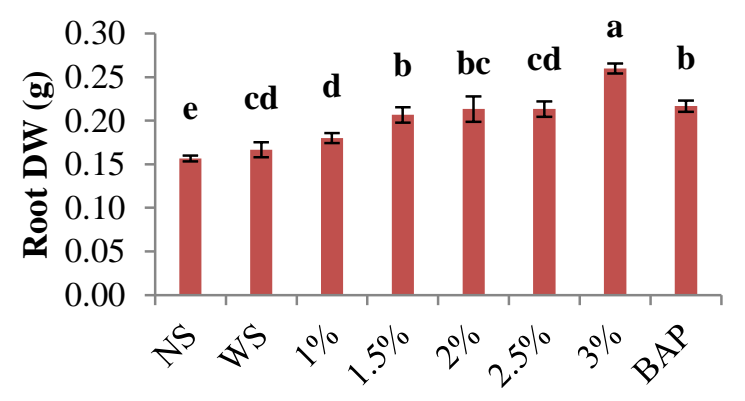

Treatments

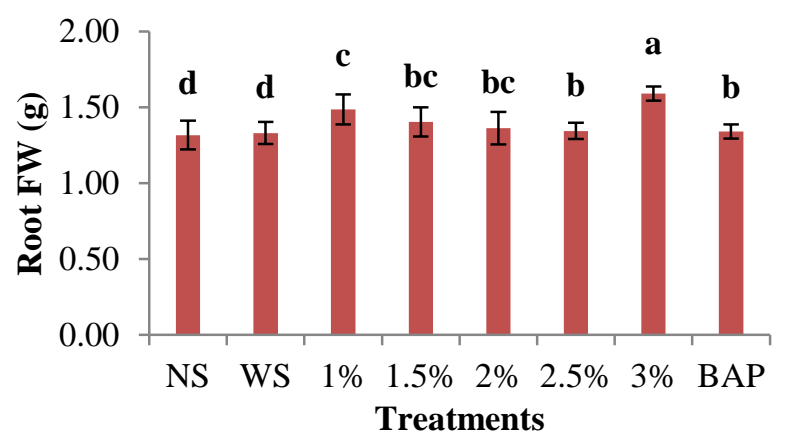

Figure-7. Root fresh weight (left) and root dry weight (right) of chickpea as influened by different concentrations of BWE. NS= No Spray, WS $=$ Water Spray, BAP= 6-Benzylaminopurine

\section{No. of leaves of chickpea seedlings}

Data regarding number of leaves of chickpea as influenced by different foliar applications showed statistically significant results (Fig. 8). Maximum leaves were achieved at foliar application of $3 \% \mathrm{BWE}$, following by the foliar BAP application and two lower concentration application at $2 \%$ and $2.5 \%$ of BWE. Whereas, other lower concentration applications (1\% and $1.5 \%$ BWE) also improve this number in comparison to no spray treatment.

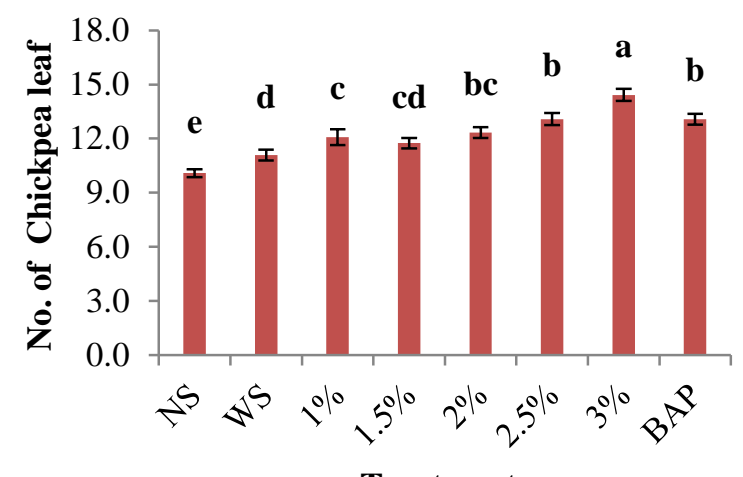

Treatments

Figure-8. No. of leaves of wheat (left) and chickpea (right) as influened by different concentrations of BWE. NS= No Spray, WS= Water Spray, BAP= 6Benzylaminopurine

\section{Discussion}

Foliar applied brassica water extract at lower concentrations $(1,1.5,2,2.5$ and 3\%) were applied on the germinated seedlings of wheat and chickpea. Seedling growth of both these test species was investigated for 20 days after germination. Brassica extract was applied as a natural growth regulator and there are several field investigations that support this idea to check it as growth regulator as foliar spray (Jahangeer, 2011; Iqbal, 2011; Awan et al., 2012; Shahzad et al., 2017). However, a synthetic growth regulator in the form of BAP was also used in the studies to compare the efficacy of both natural and synthetic sources. BAP has also been tested in many field studies as a potential growth regulator (Yasmeen et al., 2013; Bajwa and Farooq, 2017; Bajwa et al., 2018). Brassica extract possess several potential secondary metabolites viz. brassinolide, isothiocyanates glucosinolates, thiocyanates (Grove et al., 1979; Romanowski and Klenk, 2000; Agerbirk and Olsen, 2012), these have a vital action in growth actions of plants; like chlorophyll accumulation, 
photosynthesis, expansion of leaf and transpiration (Gamalero and Glick, 2011). In case of monocot specie wheat crop, BWE at only $2 \%$ concentration showed best result in all the recorded parameters like, shoot/root biomass, shoot/root length and number of leaves (Fig. 1-3). While, BAP also showed almost similar response as recorded in case of $2 \%$ BWE foliar spray, in most of the recorded parameters of the wheat, however, other concentrations of BWE also improve the aforementioned parameters in comparison to control treatments (Fig. 1-3). This optimized level of $2 \%$ BWE in seedling development study was contrary to the earlier investigated level, where researchers optimized 5\% BWE concentration for field study of wheat crop (Shahzad et al., 2017). However, the results of controlled condition experiment haven't maintained $5 \%$ concentration. In case of chickpea, a dicot representative, same level of BWE (2\%) could not gave the best results, but here all the recorded parameters performed best when we applied 3\% BWE as foliar spray (Fig. 4-6). Brassinolide, an important secondary metabolite present in brassica extract, have been tested as foliar applied growth regulator in various studies and consequently the yield and yield contributing traits of all the test crops including, maize, rice, black gram was enhanced (Yokota and Takahashi 1986; Mayumi and Shibaoka 1995; Jeyakumar et al. 2008). Moreover, these secondary metabolites are concentration dependent (Farooq et al. 2013); at higher concentration these inhibit the growth of test species while at lower concentrations these endorse the biological processes of plants and consequently growth and yield of the plants is enhanced. Similar is the case with brassica species, that possess such chemicals and there low concentration application promote the growth and among these few were named as brassins (Mitchell et al., 1970). So, from all this discussion, it is very much clear that these are secondary metaboloites which are responsible for the action of seedling development for both the test crops.

\section{Conclusion}

It can be concluded that BWE is a natural growth regulator when used in lower concentrations. Foliar application of BWE led to enhance seedling parameter like shoot/root biomass, shoot/root length and number of leaves. It can be recommended that low concentration levels of BWE at $2 \%$ and $3 \%$ are important for promoting the seedling development of wheat and chickpea respectively.

Disclaimer: None.

Conflict of Interest: None. Source of Funding: None.

\section{References}

Agerbirk N and Olsen CE, 2012. Glucosinolate structures in evolution. Phytochem. 77: 16-45.

Asgharipour MR and Armin M, 2010. Inhibitory effects of Sorghum halepens root and leaf extracts on germination and early seedling growth of widely used medicinal plants. Adv. Environ. Biol. 4:316-324.

Ashrafi YZ, Ashrafi Y, Rahnavard A, Sedigheh S, Hassan, Alizade M and Hamid M, 2008. Study of the allelopathic potential of extracts of Azadirachta indica (Neem). Online J. Biol. Sci. 8:57-61.

Awan FK, Rasheed M, Ashraf M and Khurshid MY, 2012. Efficacy of brassica, sorghum and sunflower aqueous extracts to control wheat weeds under rainfed conditions of Pothwar, Pakistan. J. Anim. Plant Sci. 22: 715-721.

Bajwa AA, Farooq M and Nawaz A, 2018. Seed priming with sorghum extracts and benzyl aminopurine improves the tolerance against salt stress in wheat (Triticum aestivum L.). Physiol. Mol. Biol. Plants. 24: 239-249.

Bajwa AA and Farooq M, 2017. Seed priming with sorghum water extract and benzyl amino purine along with surfactant improves germination metabolism and early seedling growth of wheat. Arch. Agron. Soil Sci. 63: 319-329.

Chon SU and Kim JD, 2002. Biological activity and quantification of suspected allelochemicals from alfalfa plant parts. J. Agron. Crop Sci. 188:281285

Farooq M, Bajwa AA, Cheema SA and Cheema ZA, 2013. Application of allelopathy in crop production. Int. J. Agric. Biol. 15:1367-1378

Gamalero E and Glick BR, 2011. Mechanisms used by plant growth promotion bacteria. In: Maheshwari DK ed. Bacteria in agrobiology: plant nutrient management. Berlin: SpringerVerlag.

Grove MD, Spencer GF, Rohwedder WK, Mandava NB, Worley JF, Warthen JD, Steffens GL, Flippen-Anderson JF and Cook JC, 1979. 
Brassinolide, a plant growth-promoting steroid isolated from Brassica napus pollen. Nature. 281: 216-217.

Haramoto ER and Gallandt ER, 2004. Brassica cover cropping for weed management: A review. Renew. Agric. Food System. 19(4): 187198.

Iqbal MA, 2011. Response of canola (Brassica napus L.) to foliar application of moringa (Moringa olifera L.) and brassica (Brassica napus L.) water extracts. MSc (Hons) Thesis, Department of Agronomy, University of Agriculture, Faisalabad, Pakistan

Jahangeer A, 2011. Response of maize (Zea mays L.) to foliar application of three plant water extracts. MSc (Hons) Thesis, Department of Agronomy, University of Agriculture, Faisalabad, Pakistan

Jeyakumar P, Velu G, Rajendran C, Amutha R, Savery MA and Chidambaram S, 2008. Varied responses of black gram (Vigna mungo) to certain foliar applied chemicals and plant growth regulators. Legume Res. 31: 110-113

Kordali S, Cakir A and Sutay S, 2007. Inhibitory effects of monoterpenes on seed germination and seedling growth. Zeitschrift Fur Naturforschung C-J. Biosci. 62:207-214

Mayumi K and Shibaoka H, 1995. A possible double role for brassinolide in the reorientation of cortical microtubules in the epidermal cells of azuki bean [Vigna angularis] epicotyls. Plant Cell Physiol. 36: 173-181

Mitchell JW, Mandava N, Worley JF, Plimmer JR and Smith MV, 1970. Brassins-a new family of plant hormones from rape pollen. Nature. 225:10651066.

Rehman MU, Hussain M, Ali M, Mustafa CB, Shafi J and Iqbal F, 2013. Allelopathy of Brassica. A review. Scientia. 3: 46-53

Romanowski F and Klenk H, 2000. Thiocyanates and isothiocyanates, organic; Ullmann's Encyclopedia of Industrial Chemistry [on line]. Wiley-VCH Verlag Gmb H.

Shahzad B, Cheema SA, Farooq M, Cheema ZA, Rehman A and Abbas T, 2017. Hormetic infuence of foliage applied brassica water extracts on morphological and yield attributes of bread wheat under diferent fertilizer regimes. Planta Daninha. 36: 1-12.

Siemens DH, Garner SH, Mitchell-Olds $\mathrm{T}$ and Callaway RM, 2002. Cost of defense in the context of plant competition: Brassica rapa may grow and defend. Ecol. 83: 505-517.

Steel RGD, Torrie JH and Dickey D, 1997. Principles and procedures of statistics: a biometrical approach. New York McGraw Hill Books. NY, USA.

Wada K, Marumo S, Ikekawa N, Morisaki M and Mori K, 1981. Brassinolide and homobrassinolide promotion of lamina inclination of rice seedlings. Plant Cell Physiol. 22: 323-326.

Yasmeen A, Basra SMA, Wahid A, Farooq M, Nouman W, Rehman H and Hussain N, 2013. Improving drought resistance in wheat (Triticum aestivum) by exogenous application of growth enhancers. Int. J. Agric. Biol. 15-6S: 1307-1312

Yokota $\mathrm{T}$ and Takahashi N, 1986. Transport and metabolism of brassinosteriods in rice Plant Growth Substances (ed. Bopp M), Springer Verlag, Berlin, Germany.

\section{Contribution of Authors}

Farooq O: Conceived idea, data interpretation, manuscript final reading and approval

Ali M: Designed research methodology and data interpretation

Sarwar N: Literature review, manuscript writing and data interpretation

Rehman A: Data collection and literature review Iqbal MM: Designed research methodology and literature review

Naz T: Data analysis and literature review Asghar M: Data collection, analysis and interpretation

Ehsan F: Literature review and manuscript writing Nasir M: Data collection, analysis and interpretation

Hussain QM: Data collection, analysis and interpretation

Afzal S: Literature review and manuscript writing 